\title{
Inspired by Garlic: Insights on the Chemistry of Sulfenic Acids and the Radical-Trapping Antioxidant Activity of Organosulfur Compounds
}

\begin{tabular}{|r|l|}
\hline Journal: & Canadian Journal of Chemistry \\
\hline Manuscript ID & cjc-2015-0438.R1 \\
\hline Manuscript Type: & Award Lecture \\
\hline Date Submitted by the Author: & 25-Sep-2015 \\
\hline Complete List of Authors: & $\begin{array}{l}\text { Chauvin, Jean-Philippe; University of Ottawa, Department of Chemistry } \\
\text { Zielinski, Zosia; University of Ottawa, Department of Chemistry } \\
\text { Pratt, Derek; University of Ottawa, Department of Chemistry }\end{array}$ \\
\hline Keyword: & organosulfur, antioxidants, sulfenic acid, peroxidation, garlic \\
\hline \multicolumn{2}{|c}{} \\
\hline
\end{tabular}




\title{
Inspired by Garlic: Insights on the Chemistry of Sulfenic Acids and the
}

\section{Radical-Trapping Antioxidant Activity of Organosulfur Compounds}

\author{
Jean-Philippe R. Chauvin, Zosia A. M. Zielinski and Derek A. Pratt* \\ Department of Chemistry and Biomolecular Sciences, University of Ottawa,
} Ottawa, Ontario, CANADA K1N 6 N5

\begin{abstract}
Organosulfur compounds have long been recognized as important antioxidants for the preservation of petroleum-derived products. It has also been suggested that the health benefits of garlic and related plant species can be ascribed to the radical-trapping antioxidant (RTA) activity of some of their unique organosulfur constituents, such as allicin. This account highlights our efforts to elucidate the RTA mechanisms of allicin and related plant-derived organosulfur compounds, as well as the organosulfur compounds used to preserve commercial and industrial products. ${ }^{1}$
\end{abstract}

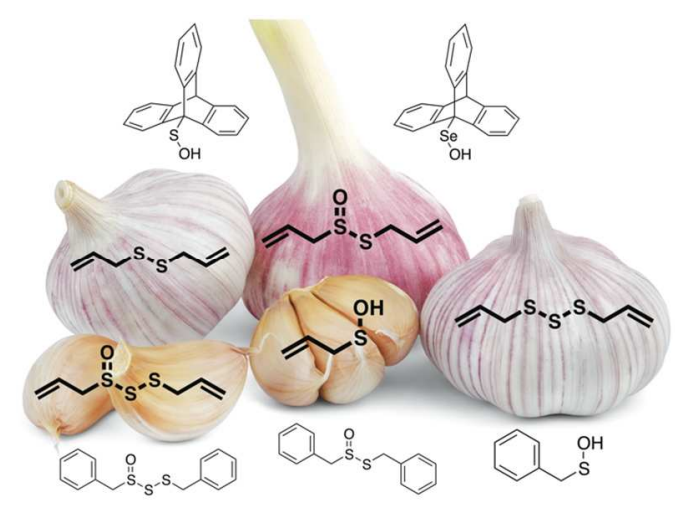

Keywords: organosulfur, antioxidants, sulfenic acid, peroxidation, garlic

1 This manuscript highlights some of the contributions recognized by the award of the 2015 Canadian Society of Chemistry Keith Fagnou Award that could not be included in the award lecture due to time constraints. For an account of the award lecture, please see Valgimigli, L.; Pratt, D. A. Acc. Chem. Res. 2015, 48, 966-975. 


\section{Introduction}

Sulfur is arguably the most important element in organic chemistry that is not found in the first row of the periodic table. In fact, after carbon and hydrogen, sulfur is the most abundant contributor to crude petroleum. ${ }^{1}$ Organosulfur compounds have a rich chemistry, largely forged in the petroleum industry, where one of their most important uses is as antioxidants. Denison and Condit ${ }^{2}$ are often credited with the observation that the removal of natural organosulfur compounds from petroleum renders the hydrocarbons much more oxidizable. In fact, although sulfur is removed from petroleum feedstocks in refining processes, it is generally added back to finished products. It is widely believed that organosulfur compounds act as antioxidants by decomposing hydroperoxides, ${ }^{3}$ the primary products of hydrocarbon autoxidation. Hydrocarbons are autoxidized to hydroperoxides by the spontaneous free radical chain reaction shown in Scheme 1 (Eq. 1-5). ${ }^{4}$ By decomposing the product hydroperoxides (Eq. 6-8), organosulfur compounds slow the rate at which new chain reactions are initiated. 


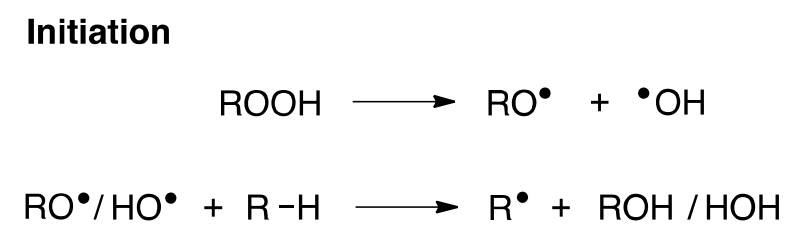

Propagation

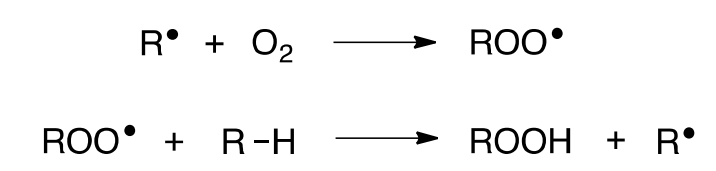

Termination

$2 \mathrm{ROO}^{\bullet} \longrightarrow$ non-radical products

Inhibition

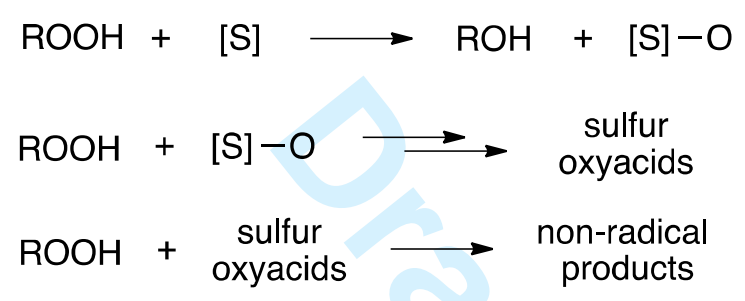

Scheme 1. Hydrocarbon autoxidation (Eqs. 1-5) and its inhibition by an organosulfur compound "[S]" (Eqs. 6-8).

Organosulfur compounds are often used to inhibit hydrocarbon autoxidation in tandem with radical-trapping antioxidants (RTAs), 5,6 such as BHT and $\alpha$ tocopherol $\left(\alpha-\mathrm{TOH}\right.$, the most biologically-active form of Vitamin E). ${ }^{7}$ Phenolic RTAs react with chain-carrying peroxyl radicals by a formal H-atom transfer mechanism, yielding a phenoxyl radical that is incapable of carrying on the chain (Eq. 9 in Scheme 2). Instead, the phenoxyl radical persists until it reacts with another radical to yield non-radical products (Eq. 10). Ideally, the second radical is another peroxyl radical, such that one phenolic RTA breaks two chain reactions. 


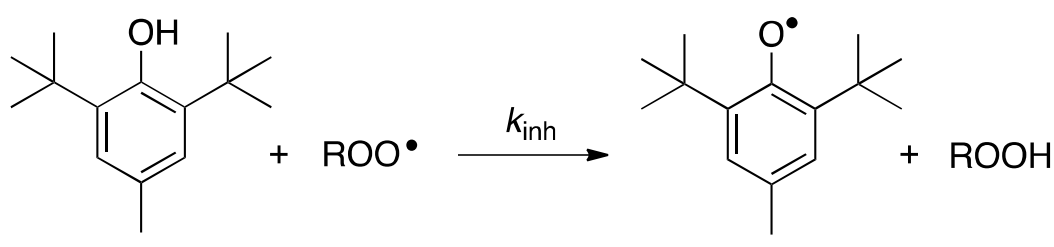

BHT

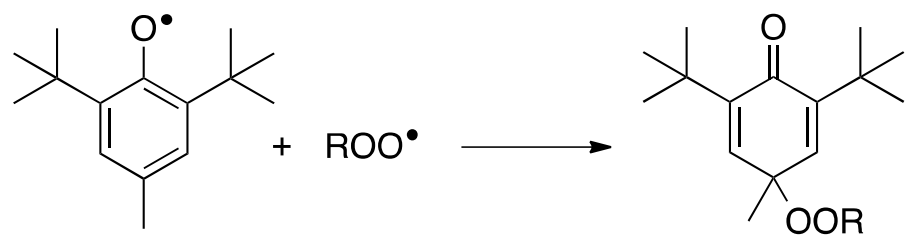

Scheme 2. The mechanism of phenolic radical-trapping antioxidants, exemplified by 2,6-di-tert-butyl-4-methylphenol (BHT).

Paralleling the abundance of sulfur in petroleum is its abundance in life, and consequently, organosulfur compounds have figured prominently in natural product chemistry, medicinal chemistry and biological chemistry. Among the richest organosulfur chemistry in Nature is that found in the genus Allium, of which garlic is the most prolific species. ${ }^{8}$ Used as a medicinal agent for millennia, garlic has proven to be a treasure trove of compounds whose study has contributed greatly to our understanding of organosulfur chemistry. ${ }^{9}$ Among the myriad of organosulfur compounds found within garlic, Cavalito was first able to ascribe its well-known antibacterial activity to a particular constituent: allicin (1). ${ }^{10}$ Allicin is formed from the non-proteinogenic amino acid alliin by the C-S lyase alliinase upon physical stress to the plant, and is believed to be garlic's primary defense against pathogens. ${ }^{8}$ 


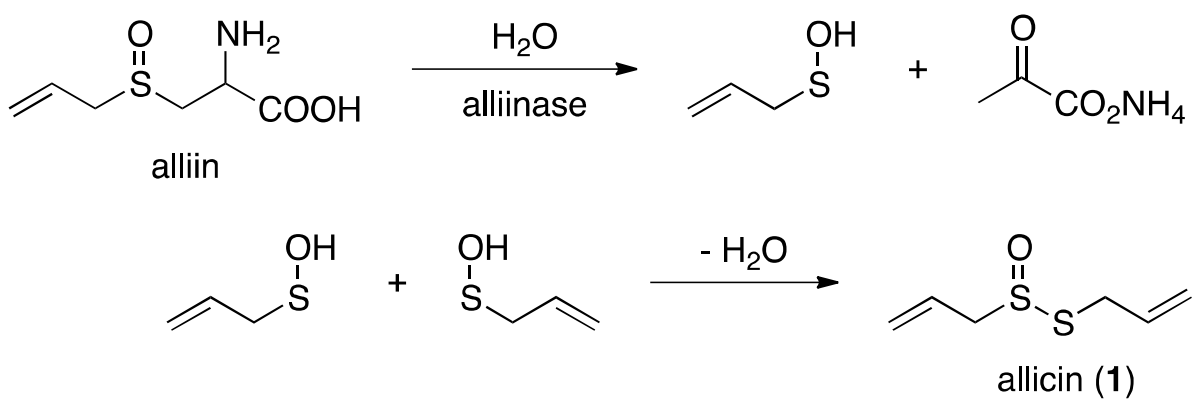

Scheme 3. The transformation of alliin to allicin.

With the rise of herbalism and the perceived benefits of naturally-sourced preventive/therapeutic agents, allicin (as well as other garlic constituents) has since been screened for numerous biological activities - most commonly 'antioxidant' activity. Prompted by the suggestion that allicin was a potent RTA, ${ }^{11-14}$ we ventured into the world of organosulfur chemistry in 2008. Since allicin is devoid of any of the typical functionalities that are found in good RTAs (e.g. a weak O-H bond, as in phenols), we initially puzzled over the mechanism responsible for this activity. Our initial mechanistic studies led us in several directions, including explorations of the fundamental reactivity of sulfenic (and selenenic acids), and mechanistic studies of the RTA activity of higher sulfides and their oxides. This account provides an overview of our findings.

\section{Allicin as a Radical-Trapping Antioxidant: The Medium Matters!}

Our initial attraction to the "garlic problem" was prompted by the implausibility of a suggested mechanism ${ }^{14}$ for the reaction of allicin with peroxyl radicals: 


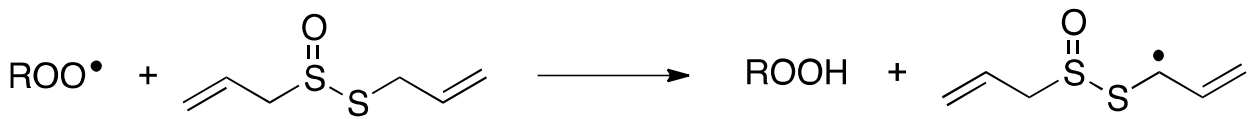

1

Amorati and Pedulli also recognized this ${ }^{15}$ and demonstrated unambiguously that $\mathrm{H}$ atom donation from a methylene group flanked by a double bond and a sulfur atom (in diallyl disulfide) cannot be responsible for the RTA activity of allicin. In fact, they measured a rate constant for the reaction of cumene-derived peroxyl radicals and diallyl disulfide of $\sim 1.6 \mathrm{M}^{-1} \mathrm{~s}^{-1}$, which is similar to the rate constant for the propagation of cumene autoxidation. ${ }^{15}$ The introduction of an oxygen atom on one of the sulfur atoms in diallyl disulfide - as in allicin - was not expected to change the lability of the $\mathrm{H}$-atom on the distal methylene unit (the calculated C-H BDEs using the eminently reliable CBS-QB3 methodology are 82.4 and $81.8 \mathrm{kcal} / \mathrm{mol}$, respectively). ${ }^{16}$ However, oxygenation of one of the sulfur atoms does enable the very facile Cope-type elimination of a sulfenic acid from the thiosulfinate (Eq. 14): ${ }^{8}$

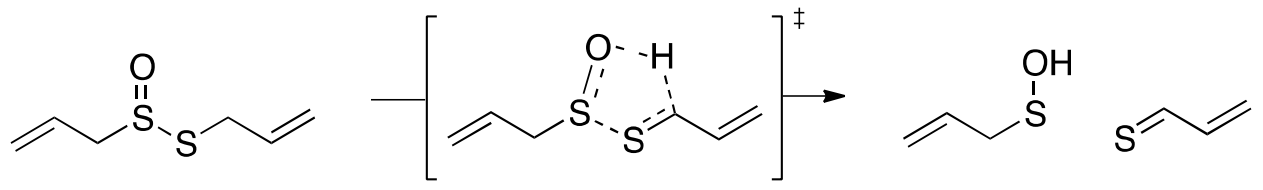

We surmised that the 2-propenesulfenic acid derived from allicin would be an excellent $\mathrm{H}$-atom donor. ${ }^{17}$ In fact, it turned out that this wasn't the first suggestion that a sulfenic acid would react quickly with peroxyl radicals; Koelwijn and Berger had invoked the Cope-type elimination of $\alpha, \alpha$-dimethylethanesulfenic acid from ditert-butylsulfoxide to explain the RTA activity of the latter years before (Eq. 15). ${ }^{18}$ 


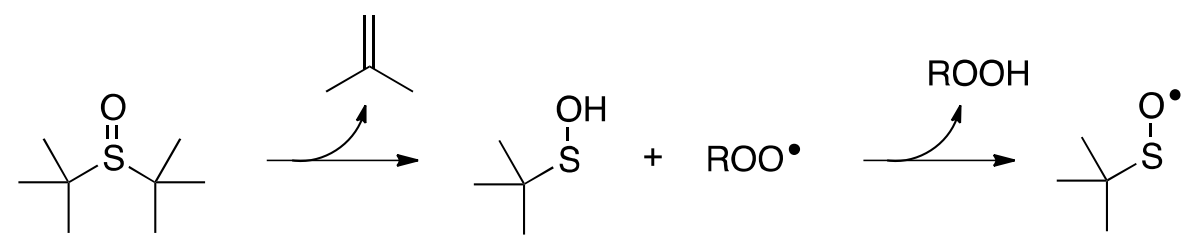

Sulfenic acids are notoriously unstable, ${ }^{19}$ and readily self-condense to yield a thiosulfinate (among other possible reaction pathways). However, since H-bonding solvents are known to slow Cope elimination from allicin, ${ }^{20}$ we provided indirect evidence for the role of the Cope elimination in the RTA activity of allicin simply by demonstrating that this activity disappears in the presence of a good H-bond donor, such as 1,1,1,3,3,3-hexafluoro-2-propanol. ${ }^{17}$ In order to bolster support for the mechanism we also carried out computations, which revealed that sulfenic acids have among the weakest $\mathrm{O}-\mathrm{H}$ bonds known (ca. $69 \mathrm{kcal} / \mathrm{mol}$, roughly the same as in hydroxylamines). ${ }^{17}$ Moreover, sulfenic acids were predicted to undergo barrier-less reactions with peroxyl radicals via a transition state (TS) with significant overlap between orbitals on the sulfur atom of the sulfenic acid and the inner oxygen atom of the peroxyl radical (a syn TS, Figure 1A). ${ }^{17}$ This secondary orbital interaction (cf. Figure 1B) appears to be key to the tremendous reactivity of sulfenic acids with peroxyl radicals since the TS structure that minimizes the interaction between the groups on the reacting moieties (anti TS, Figure 1A) is significantly higher in energy. 
A
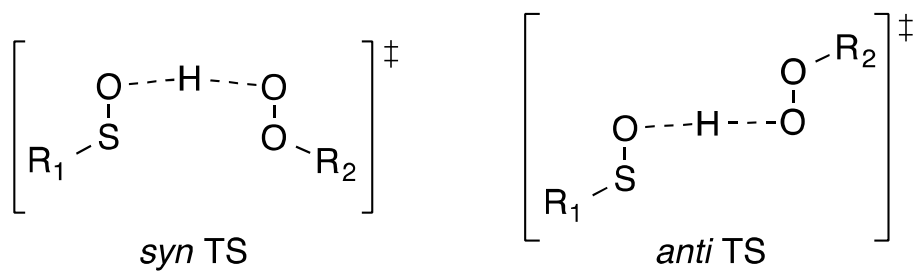

B

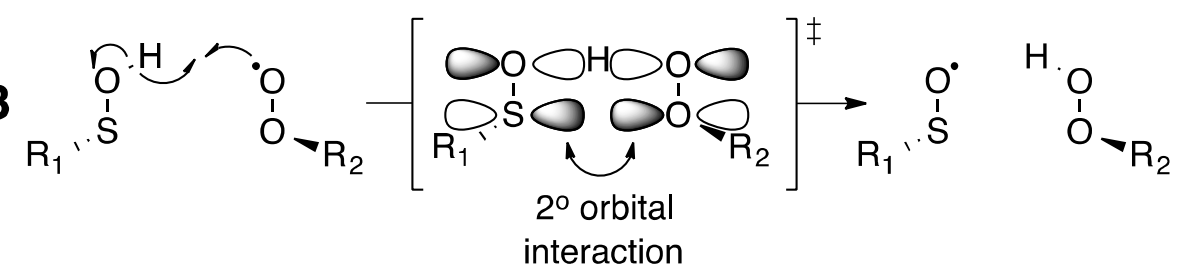

Figure 1. Schematic depiction of the reaction of a sulfenic acid with a peroxyl radical with either a syn or anti transition state geometry (A). Schematic representation of the secondary orbital interaction that leads to a preference for the syn TS (B).

As a control experiment, we examined the reactivity of $S$-propyl propanethiosulfinate (2), the saturated analog of allicin, which lacks an activated C$\mathrm{H}$ bond to enable Cope elimination. Indeed, this compound was a poor inhibitor of

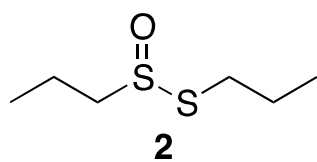

autoxidation (ca. 1000-fold less reactive); better than the corresponding disulfide, but not as good as allicin - more on this later. We also studied the dibenzyl analog of allicin (petivericin, 3), which derives from garlic's relative Petiveria alliacae. Interestingly, petivericin is commonly used in the South and Central Americas in many of the same medicinal applications wherein garlic has been used in Asia. ${ }^{21,22}$ Although petivericin had indistinguishable RTA activity from allicin - including the 
abolishment of this activity in the presence of strong H-bond donating solvents that slow Cope elimination - it is of far greater relative stability because sulfenic acid formation is reversible. ${ }^{16}$

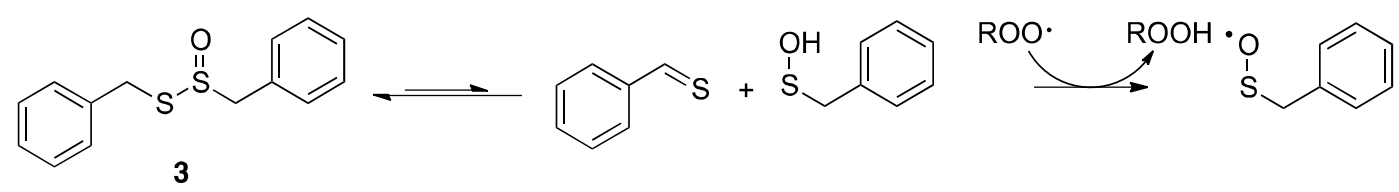

Due to the reversibility of the Cope elimination from petivericin, we were able to fit data obtained from autoxidations inhibited by it to the standard kinetic scheme for RTA-inhibited autoxidations and estimate a rate constant for the reaction of $\alpha$-toluenesulfenic acid with peroxyl radicals, $k_{\text {inh }}=3 \times 10^{7} \mathrm{M}^{-1} \mathrm{~s}^{-1} .^{23}$ This rate constant, being ten-fold greater than that for the reaction of $\alpha$-TOH and peroxyl radicals and among the largest ever reported for an RTA, agreed well with our earlier computations. ${ }^{17}$

It was left to see if this mechanism could operate under biologically relevant conditions. To do so, we employed a fluorogenic probe developed by Gonzalo Cosa and his team for measuring antioxidant status in lipid bilayers. ${ }^{24}$ The probe, which consists of a BODIPY fluorophore connected to the reactive head group of $\alpha$-TOH, reacts competitively with added antioxidants for peroxyl radicals - with more effective ones suppressing probe oxidation. ${ }^{25}$ Interestingly, both thiosulfinates were completely ineffective at suppressing probe oxidation in unilammelar liposomes, implying that the rates of their reactions with peroxyl radicals in lipid bilayers were at least 100 -fold less than $\alpha$-TOH. We surmised that this was because the sulfenic 
acids derived from both allicin and petivericin could partition to the surrounding aqueous medium - away from lipid-derived peroxyl radicals - where they would undergo other (non-RTA) reactions. To test this hypothesis, we synthesized a hexylated analogue of petivericin (4), with the anticipation that the more lipophilic

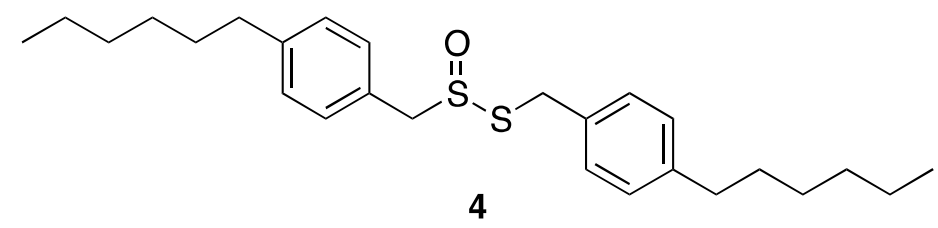

substituent would better anchor the sulfenic acid derived from Cope elimination in the lipid bilayer. ${ }^{26}$ Whilst the hexylated petivericin yielded measurable RTA activity (cf. retarding of the initial rate of fluorescence increase in Figure $2 \mathrm{C}$ relative to Figures 2A and 2B), it was still quite poor compared to established RTAs, such as $\alpha$ TOH. ${ }^{25,26}$ However, since sulfenic acid formation from thiosulfinates can also be achieved via reaction with a good nucleophile, such as a thiol, we also investigated whether sulfenic acid formation could be promoted by addition of $N$-acetylcysteine (NAC) to the buffer in which the liposomes were suspended. While doing so had no effect on the (lack of) activity of allicin and petivericin, a remarkable effect was observed on the hexylated petivericin-inhibited oxidations (cf. Figure 2D). ${ }^{26}$ In fact, the combination of hexylated petivericin and an equivalent of NAC made for a more effective RTA than $\alpha$-TOH! Moreover, the addition of more than one equivalent of NAC prolonged the inhibited period further. 

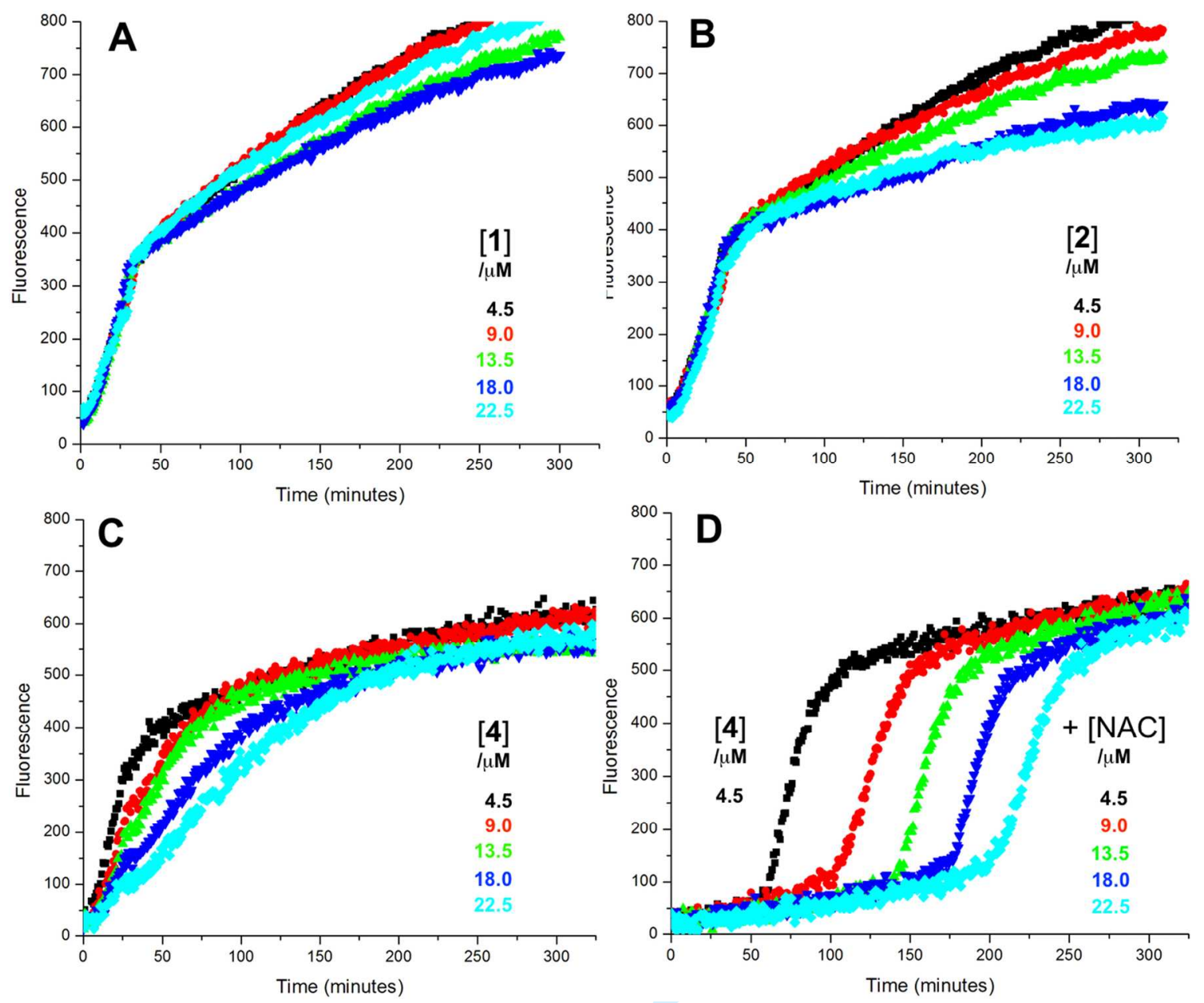

Figure 2. Fluorescence (at $520 \mathrm{~nm}$ ) intensity-time profiles from MeOAMVN mediated ( $0.2 \mathrm{mM})$ oxidations of egg phosphatidylcholine liposomes (1 $\mathrm{mM})$ containing $0.15 \mathrm{mM} \mathrm{H}_{2} \mathrm{~B}-\mathrm{PMHC}$ and increasing concentrations of $\mathbf{1}$ (A), 2 (B) and 4 (C), and $\mathbf{4}$ with increasing concentrations of NAC (D).

These results could be explained by a mechanism wherein the sulfinyl radical formed following $\mathrm{H}$-atom transfer from the sulfenic acid is regenerated by reaction with NAC (Figure 3). ${ }^{26}$ 


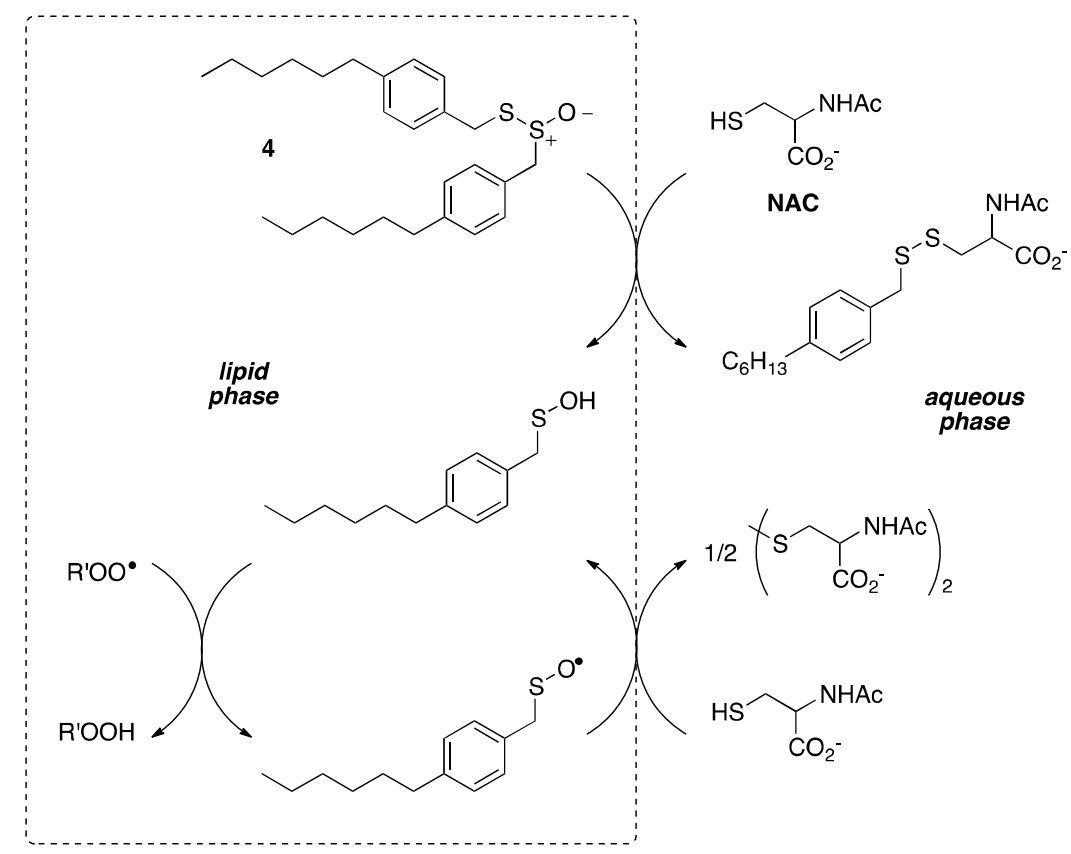

Figure 3. Proposed mechanism for the radical-trapping antioxidant activity of $\mathbf{4}$ in the presence of $N$-acetylcysteine (NAC).

Most recently, we extended these studies to human cell culture. ${ }^{27}$ In this context, allicin and petivericin only appear to inhibit lipid peroxidation in cells (e.g. with IC $_{50}$ values of $20 \mu \mathrm{M}$ and $23 \mu \mathrm{M}$, respectively, in Tf1a erythroblasts); in fact, they simply kill the cells (e.g. with $\mathrm{TC}_{50}$ values of $39 \mu \mathrm{M}$ and $56 \mu \mathrm{M}$, respectively, in the same cell line). Similar results were observed in other cell lines and can be ascribed to allicin's (and petivericin's) electrophilic reactivity, which leads to depletion of glutathione and/or reaction with nucleophilic cysteine residues on proapoptotic signaling proteins. Thus, allicin (and petivericin) should not be described as antioxidants in biological contexts. In contrast, hexylated petivericin inhibited lipid peroxidation (e.g. with an $\mathrm{IC}_{50}$ value of $74 \mu \mathrm{M}$ in $\mathrm{Tf} 1 \mathrm{a}$ erythroblasts), but was not toxic to cells. ${ }^{27}$ Moreover, its efficacy improved when lipid peroxidation was 
initiated by inhibition of glutathione peroxidase-4 rather than via glutathione depletion, suggesting a role for glutathione in the activity of the compound (akin to the role of NAC in the liposome experiments). These results imply that hexylated petivericin behaves as an RTA in cells and reinforce the notion that allicin and petivericin do not. This is because the allicin- and petivericin-derived sulfenic acids partition to the cytosol where they are consumed by other (non-RTA) reactions.

\section{The Taming of the Shrew: Exploring the Reactivity of Sulfenic Acids}

Over the course of the foregoing studies it became increasingly clear that the ideal demonstration of the intervention of sulfenic acids in the RTA activity of allicin and petivericin (and hexylated petivericin) would be to directly study the radical reactivity of the sulfenic acids derived therefrom. Sadly, this is an impossible task, since unhindered sulfenic acids self-condense to thiosulfinates too rapidly to be observed. ${ }^{19}$ In fact, only a handful of sulfenic acids that are sufficiently persistent for study have been prepared. ${ }^{28}$ One such hindered sulfenic acid, 9-triptycenesulfenic acid (5),29 was prepared using a modified literature procedure, and experiments were designed to shed light on the radical reactivity of sulfenic acids, in general. ${ }^{30}$

To provide thermodynamic support for the RTA reactivity of sulfenic acids, and confirmation of the weak O-H BDE computed for them in earlier work $(\sim 69$ $\mathrm{kcal} / \mathrm{mol}$ ), EPR equilibration experiments with 9-triptycenesulfenic acid and the persistent nitroxide TEMPO (Eq. 17) were carried out in collaboration with Luca Valgimigli at the University of Bologna. These experiments yielded an experimental 0 -H BDE of $71.9 \pm 0.3 \mathrm{kcal} / \mathrm{mol}^{23}$ The very weak $0-\mathrm{H}$ bond - roughly $14 \mathrm{kcal} / \mathrm{mol}$ 
weaker than that in valence isoelectronic hydroperoxides $(\sim 86 \mathrm{kcal} / \mathrm{mol})-$ was ascribed to the significant spin delocalization onto the internal S-atom $(\sim 50 \%)$ in the sulfinyl radical. ${ }^{30}$

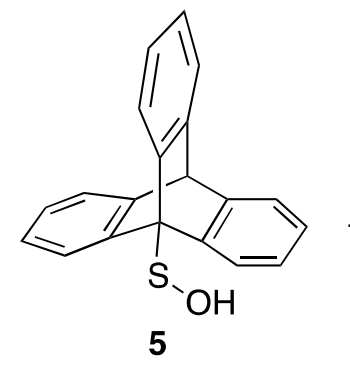

$\mathrm{O}-\mathrm{H} \mathrm{BDE}=$ $71.9 \mathrm{kcal} / \mathrm{mol}$

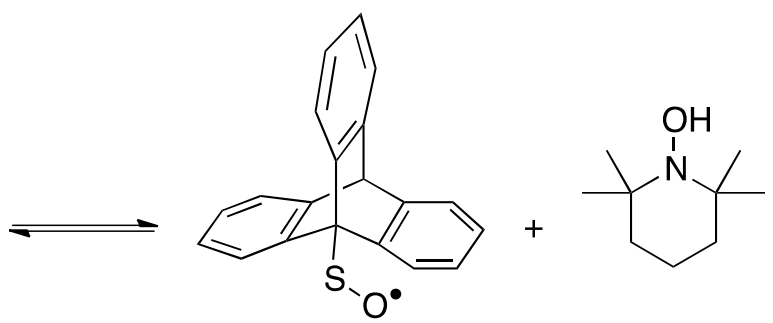

$\mathrm{O}-\mathrm{H} \mathrm{BDE}=$ $69.6 \mathrm{kcal} / \mathrm{mol}$

9-Triptycenesulfenic acid was also used to inhibit the AIBN-initiated autoxidation of styrene, enabling the derivation of a rate constant for its reaction with chain-carrying peroxyl radicals, $k_{\text {inh }}=3.0 \times 10^{6} \mathrm{M}^{-1} \mathrm{~s}^{-1}$ (in chlorobenzene) ${ }^{23}$ essentially the same as that of $\alpha$-TOH $\left(3.2 \times 10^{6} \mathrm{M}^{-1} \mathrm{~s}^{-1}\right) .{ }^{7}$ While this value was an order of magnitude slower than the value determined for the $\alpha$-toluenesulfenic acid derived from petivericin $\left(3 \times 10^{7} \mathrm{M}^{-1} \mathrm{~s}^{-1}\right),{ }^{23}$ kinetic solvent effects and kinetic isotope effects were consistent with the same $\mathrm{H}$-atom transfer mechanism for both sulfenic acids. The difference in rate constants was attributed to the steric bulkiness of the triptycyl moiety relative to benzyl, which should hinder formation of the preferred syn TS for the formal H-atom transfer - more on this later. The inhibited autoxidation data also afforded a stoichiometric factor of 0.4 for 9triptycenesulfenic acid, indicating that sulfenic acids trap significantly fewer peroxyl radicals than do phenols (Scheme 2), and suggesting that the fate of the sulfinyl radical is more complicated than its simple combination with peroxyl radicals. ${ }^{23}$ 
Tandem to the liposome studies with allicin and petivericin, the radicaltrapping ability of the persistent sulfenic acid was also investigated in liposomes. ${ }^{26}$ Interestingly, the high reactivity of the compound translated from solution to the biphasic environment of the liposomes; in fact, $\mathbf{5}$ was found to be 10 -fold more reactive than $\alpha-\mathrm{TOH}^{26}$ In addition, it displayed the same powerful co-antioxidant cooperativity with NAC as did hexylated petivericin, ${ }^{26}$ lending unequivocal support to the suggestion that a thiol can regenerate a sulfenic acid from its sulfinyl radical in biphasic systems.

We subsequently followed our academic curiosity to investigate the heavier chalcogen analogue of the sulfenic acid, and thus synthesized the corresponding persistent 9-triptyceneselenenic acid (6). ${ }^{31}$ Based on the periodic trend of weakening bonds in RO-H > RS-H > RSe-H, we wondered if a selenenic acid would have a weaker $\mathrm{O}-\mathrm{H}$ bond than a sulfenic acid, which is already considerably weaker than in a hydroperoxide (vide supra). Interestingly, radical equilibration EPR experiments with 2,4,6-tri-tert-butylphenoxyl yielded an 0 - $\mathrm{H}$ BDE of $80.9 \pm 0.9$ $\mathrm{kcal} / \mathrm{mol}$ in 9-triptyceneselenenic acid: $9 \mathrm{kcal} / \mathrm{mol}$ stronger than the sulfenic acid, and actually more similar to a hydroperoxide (ca. $86 \mathrm{kcal} / \mathrm{mol}) .{ }^{31}$ We surmised that the longer Se-O bond in the selenenyl radical precludes radical delocalization onto the internal selenium atom $(\sim 20 \%)$ relative to the sulfur atom in the sulfinyl radical $(\sim 50 \%){ }^{31}$ 


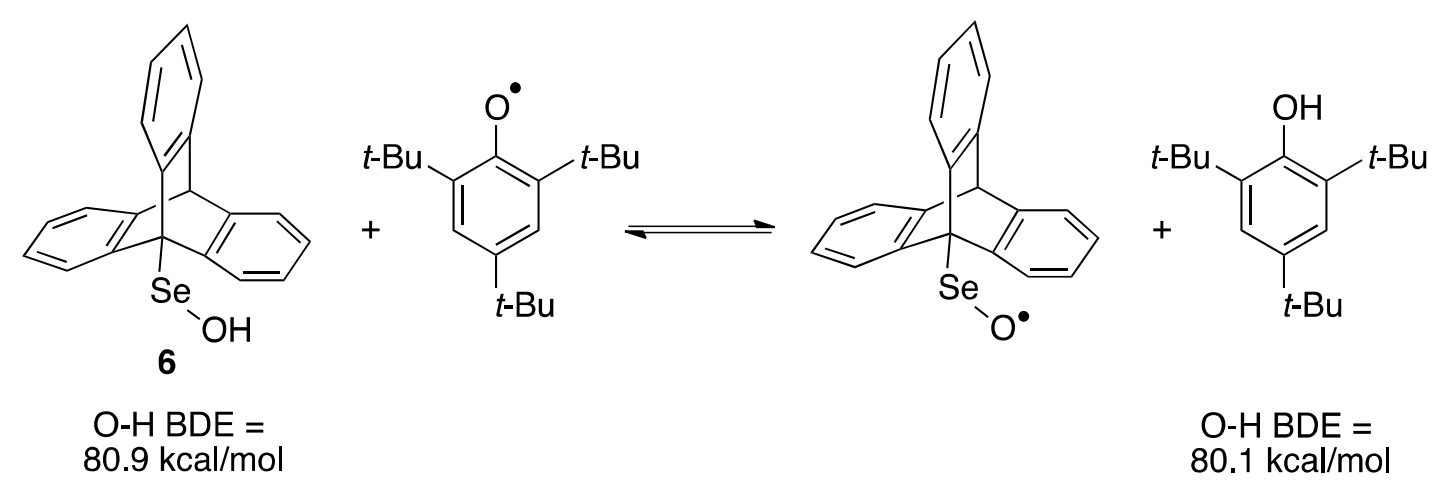

Despite its relatively strong $\mathrm{O}-\mathrm{H}$ bond, the selenenic acid underwent very rapid reactions with peroxyl radicals. The $k_{\text {inh }}$ was determined to be $1.7 \times 10^{5} \mathrm{M}^{-1} \mathrm{~s}^{-1}$ in a styrene inhibited autoxidation at $30^{\circ} \mathrm{C}$ in chlorobenzene. ${ }^{31}$ While this value is an order of magnitude smaller than in the analogous sulfenic acid $\left(3.0 \times 10^{6} \mathrm{M}^{-1} \mathrm{~s}^{-1}\right.$ under the same conditions), ${ }^{30}$ it is remarkably large given the $9 \mathrm{kcal} / \mathrm{mol}$ difference in $\mathrm{O}-\mathrm{H}$ bond strength (also considering the $k_{\text {inh }}$ for a hydroperoxide is only $\sim 10^{3} \mathrm{M}^{-1} \mathrm{~s}^{-1}$ ). ${ }^{32}$ Kinetic isotope effects and kinetic solvent effects were also consistent with a formal $\mathrm{H}$-atom transfer mechanism. ${ }^{31}$

To help explain the surprisingly similar reactivity of the sulfenic and selenenic acids towards peroxyl radicals, we undertook a parallel computational investigation. We had previously ascribed the slower-than-expected reactivity of 9triptycenesulfenic acid $\left(3 \times 10^{6} \mathrm{M}^{-1} \mathrm{~s}^{-1}\right.$ vs. $3 \times 10^{7} \mathrm{M}^{-1} \mathrm{~s}^{-1}$ derived for $\alpha$-toluenesulfenic acid) to steric hindrance precluding formation of the preferred syn TS. ${ }^{30}$ Surprisingly, our calculations showed that the triptycene-substituted derivatives still preferentially adopt syn TSs - and importantly, they correctly predicted that the rate constant for the reaction of 9-triptycenesulfenic acid with peroxyl radicals should be 10-fold larger than for the corresponding selenenic acid. More 
interestingly, subsequent calculations on unhindered sulfenic and selenenic acids indicated that the latter should actually be more reactive! Thus, while the triptycene moiety did not preclude the reaction taking place via a syn TS, it did preclude achieving the optimal geometry for the reaction - which gives rise to a lower barrier when Se is replaced for S despite the fact that the SeO-H bond is $9 \mathrm{kcal} / \mathrm{mol}$ stronger than the SO-H bond. We surmised that this enhanced reactivity was due to the secondary orbital interaction in the TS between the internal chalcogen atom ( $\mathrm{S}$ or Se) and the internal peroxyl oxygen (that can be seen in the calculated highest fully occupied MO, Figure 4) - an effect that is greater for selenium due to its higher energy lone pair. ${ }^{31}$

A

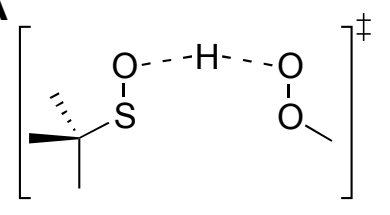

C<smiles>CC1(C)CC1OOCOOC1CCCC1</smiles>

B
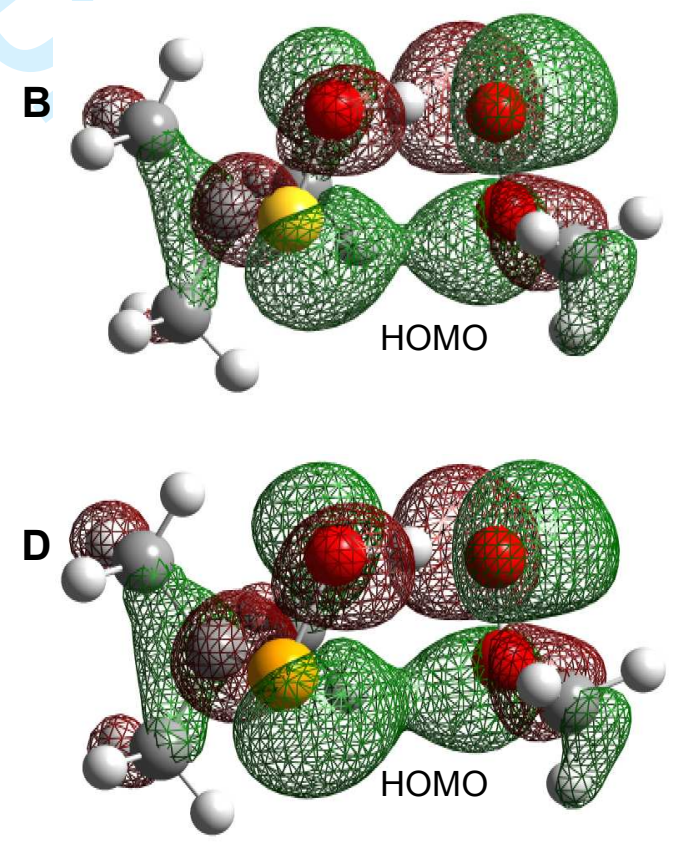

Figure 4. The syn transition states for a model tert-butylsulfenic acid (top) and tertbutylselenenic acid (bottom) and the corresponding highest fully occupied molecular orbitals (right). 
It should be pointed out that the calculated TS structures and the corresponding MOs in Figure 4 reveal that the schematic representation of the reaction of a sulfenic acid and a peroxyl radical in Figure $1 \mathrm{~B}$ is an oversimplification. In fact, the calculated TS structures display characteristics of both the ideal H-atom transfer mechanism shown in Figure 1B, and the ideal proton-coupled electron transfer (PCET) mechanism, represented schematically in Figure 5. In the PCET mechanism, the proton is transferred between non-bonding orbitals (lone pairs) in the plane of the local molecular framework, while the electron is transferred between the $\pi^{*}$ HOMO of the sulfenic acid and the $\pi^{*}$-SOMO of the peroxyl radical, which are nominally orthogonal to the local molecular framework.

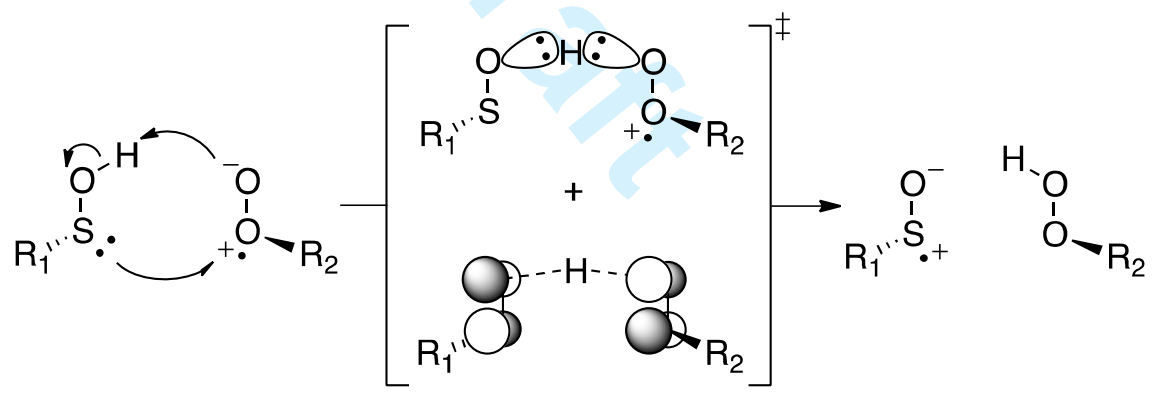

Figure 5. Schematic representation of the pairs of interacting orbitals in the protoncoupled electron transfer reaction between a sulfenic acid and a peroxyl radical .

Given the persistence of 9-triptycenesulfenic acid, we wondered if we could use it as a platform to investigate other reactions of sulfenic acids. Of particular interest to us are reactions mediated by biologically relevant oxidants, such as $\mathrm{H}_{2} \mathrm{O}_{2}$. Investigations of the kinetics and mechanism of the oxidation of a thiol to a sulfenic 
acid (and sulfinic and sulfonic acids) has been complicated by the fact that the reaction doesn't stop at the sulfenic acid, ${ }^{33}$ instead going on to the disulfide or the thiosulfinate. Since the 9-triptycenesulfenic acid does not self-condense to the thiosulfinate, we felt that it would be possible to determine the kinetics and mechanisms of the succession of reactions starting from 9-triptycenethiol as in Figure 6. In preliminary work where we have used fluorine-labeled compounds in order to monitor the reactions directly by ${ }^{19} \mathrm{~F}$ NMR, we have shown this to be possible, and have found that each of the reactions are specific base-catalyzed and at basic $\mathrm{pH}$ follow the reactivity order: $\mathrm{RSH} \approx \mathrm{RSOH}>\mathrm{RSO}_{2} \mathrm{H} .{ }^{34}$ We are currently extending these studies to other oxidants and other reaction paths for sulfenic acids.

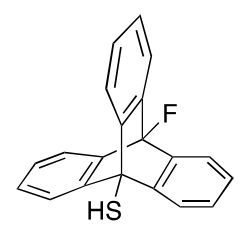

7
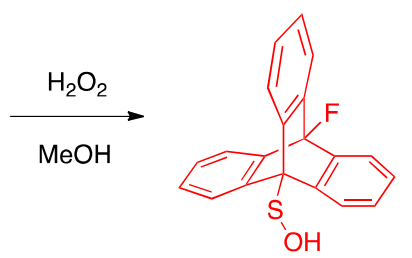

8

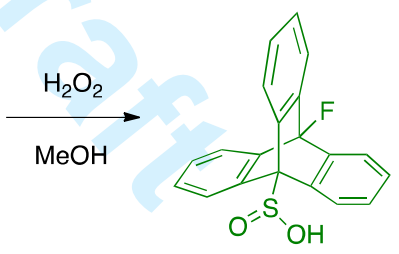

9

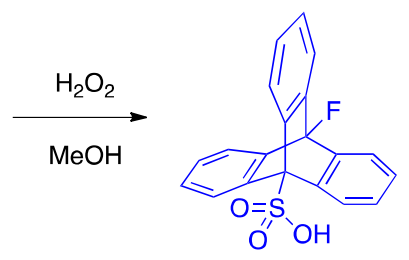

10 


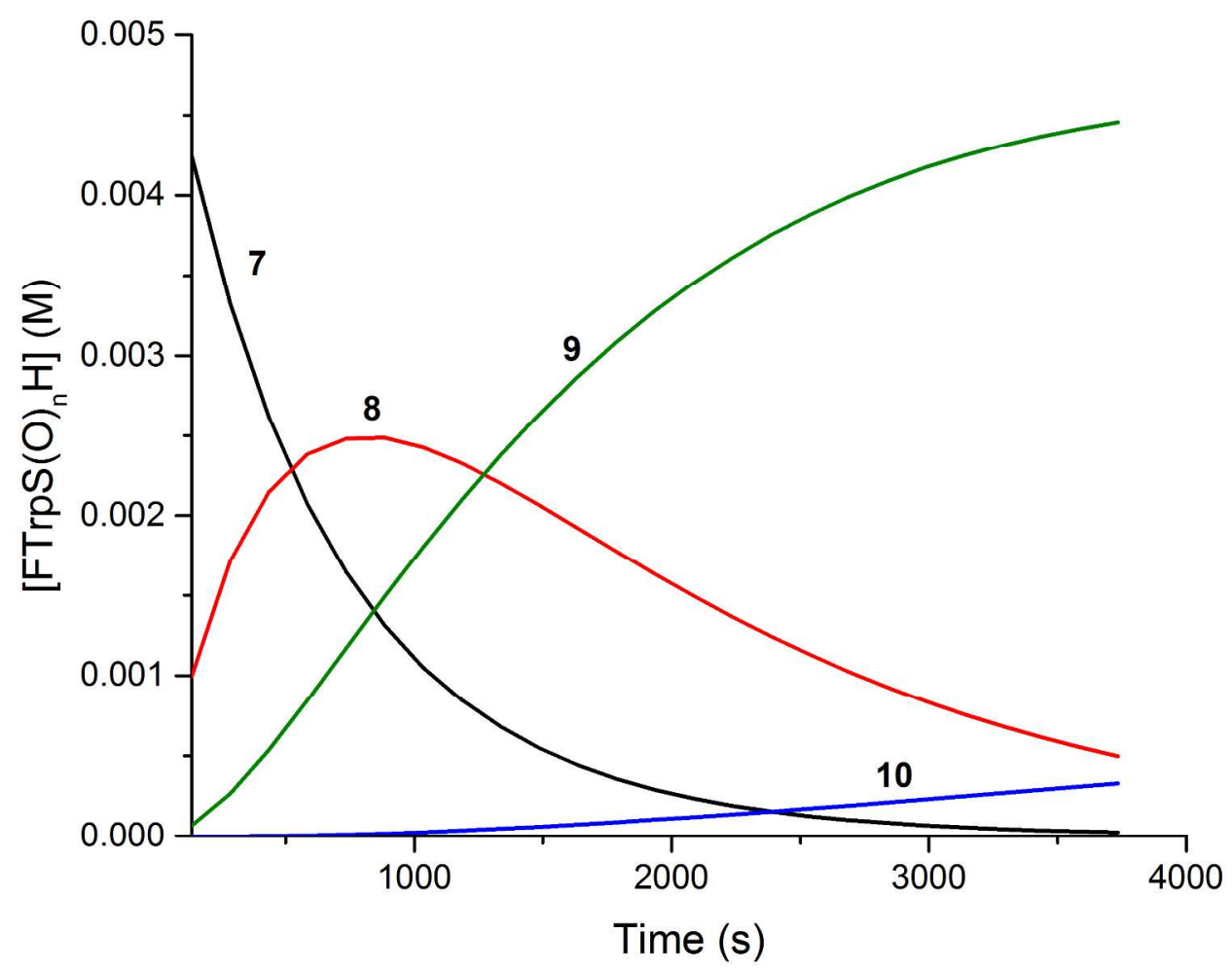

Figure 6. Reaction of $7(5 \mathrm{mM})$ with hydrogen peroxide $(50 \mathrm{mM})$ in methanol at ${ }_{\mathrm{s}}^{\mathrm{s}} \mathrm{pH}=11.5$, containing $20 \mathrm{mM}$ 2,2,6,6-tetramethylpiperidine hydrochloride.

\section{Trisulfides, their Oxides and Higher Organosulfurs: Surprising Insights}

Once satisfied with our understanding of allicin and petivericin's reactivity toward peroxyl radicals, we wondered how the incorporation of additional sulfur atoms in these molecules would impact their reactivity. In fact, trisulfides and higher polysulfides are important antioxidant additives to lubricants and other fossil fuelderived products, ${ }^{35}$ and it has long been suggested that oxidation is required to 'activate' them (it is implied that oxidation to sulfur oxyacids is necessary, and these acids promote non-radical decomposition of hydroperoxides). ${ }^{3}$ Moreover, diallyl trisulfide is among the compounds widely believed to be responsible for garlic's 
health benefits, ${ }^{36,37,38}$ and is presumably readily oxidized to its 1 -oxide. ${ }^{39} \mathrm{We}$ wondered if peroxyl radical reactivity could be relevant for these compounds, too.

When we applied the same experimental approaches to study the RTA activity of dibenzyl trisulfide-1-oxide as we had in our studies with petivericin (and allicin), we were somewhat surprised to find that it had similar activity. ${ }^{40}$ In comparison, dibenzyl trisulfide (like dibenzyl disulfide) reacted very slowly with peroxyl radicals. ${ }^{40}$ So, as was true for the disulfides and their corresponding thiosulfinates, introduction of a single oxygen atom on the trisulfide to give a trisulfide-1-oxide increases its reactivity with peroxyl radicals dramatically.

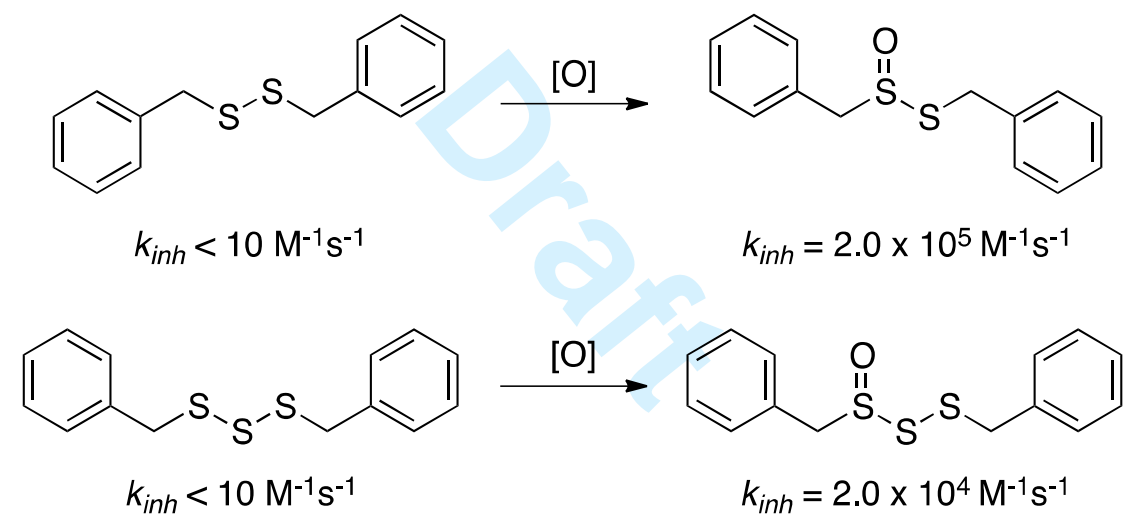

While one can draw a mechanism involving a six-center Cope-type elimination to form what would likely be a good H-atom donor (analogously to what transpires in reactions of petivericin and allicin) this seemed an unlikely mechanism. CBS-QB3 calculations supported this view; the barrier for the elimination was predicted to be $22.6 \mathrm{kcal} / \mathrm{mol}$ higher than in petivericin. ${ }^{40}$ Moreover, kinetic isotope effects determined for the reactions of $\operatorname{di}(\alpha, \alpha$-dideuteriobenzyl)trisulfide-1-oxide with peroxyl radicals $\left(k_{\mathrm{H}} / k_{\mathrm{D}}=1-2\right)^{40}$ were much smaller than those obtained from 
experiments with the corresponding deuterated petivericin analog $\left(k_{\mathrm{H}} / k_{\mathrm{D}}=18.4\right) \cdot{ }^{23}$ The lack of requirement for activated $\mathrm{H}$-atoms in the reactivity of trisulfide-1-oxides became unequivocal when a similar rate constant was determined for the reaction of di-tert-butyl trisulfide-1-oxide with peroxyl radicals $\left(k_{\text {inh }}=1.0 \times 10^{4} \mathrm{M}^{-1} \mathrm{~s}^{-1}\right) .40$

Clearly, another mechanism must exist - and if not $\mathrm{H}$-atom transfer to a peroxyl radical, it must be a radical addition and/or substitution. While further computational investigations failed to identify a radical addition pathway for this reaction, a low energy path for a concerted homolytic substitution $\left(\mathrm{S}_{\mathrm{H}}{ }^{2}\right)$ on the oxidized sulfur atom of the trisulfide-1-oxide to form a peroxysulfinate ester and a perthiyl radical could be readily identified (Figure 7).40 Gratifyingly, the barrier for this process $\left(\Delta G^{\ddagger}=15.1 \mathrm{kcal} / \mathrm{mol}\right.$ by CBS-QB3) was fully consistent with the observed kinetics. It seems reasonable to suggest that the peroxysulfinate ester formed will rearrange to a sulfonate ester, while the perthiyl radical likely reacts with $\mathrm{O}_{2}$ to liberate $\mathrm{SO}_{2}$ and produce a thiyl radical, ${ }^{41}$ for an overall stoichiometry of 1 - also in agreement with experimental observations. ${ }^{40}$ 


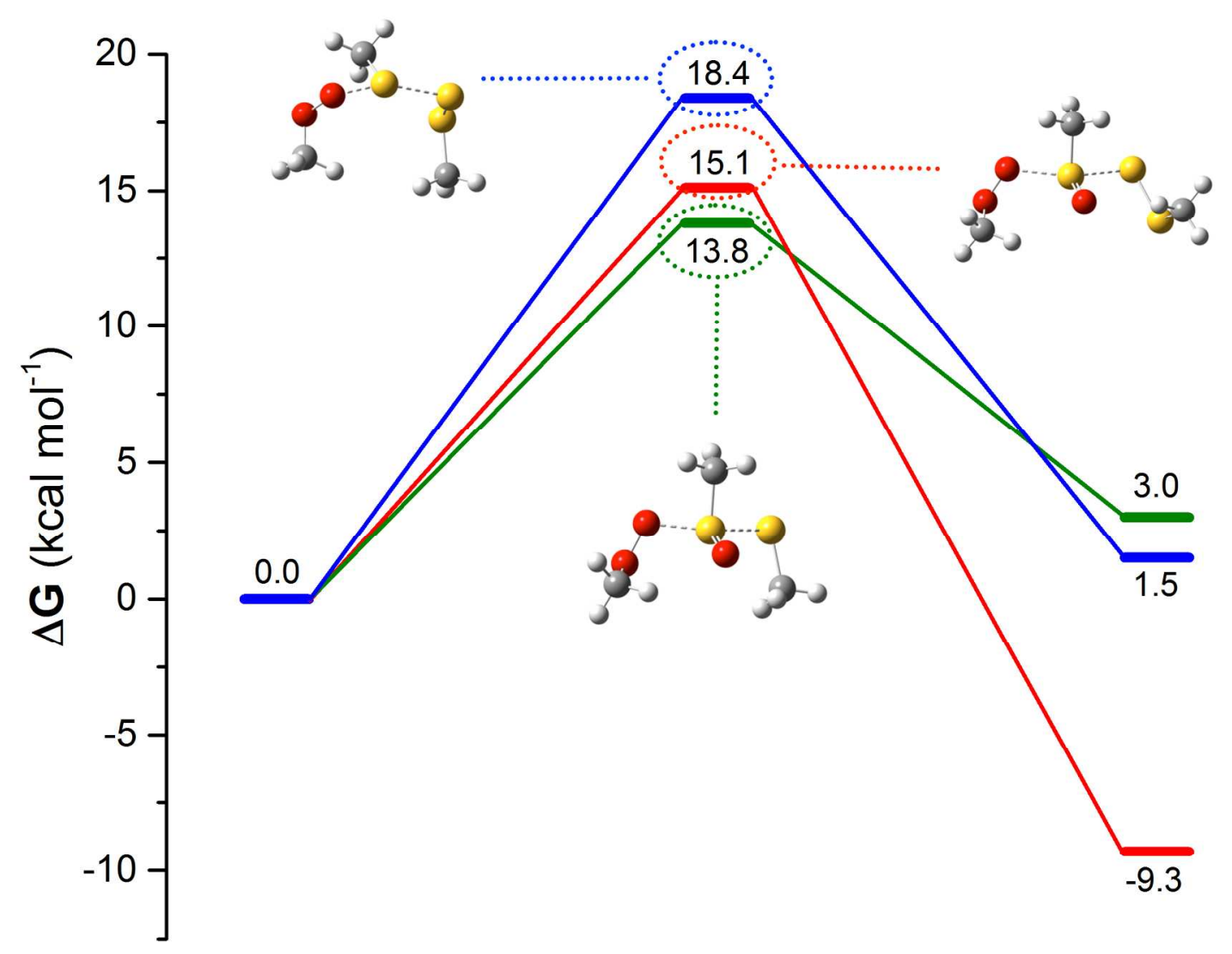

Figure 7. Methylperoxyl substitution onto $S_{1}$ of dimethyl thiosulfinate $(-)$, dimethyl trisulfide $(-)$, and dimethyl trisulfide-1-oxide $(-)$.

The corresponding TS for the reaction of a peroxyl radical with a trisulfide is $3 \mathrm{kcal} / \mathrm{mol}$ higher (consistent with the lesser reactivity observed in experiments) and slightly endergonic, due to the stronger S-S bond in the trisulfide relative to the trisulfide-1-oxide. While a similar low energy TS structure exists for the reaction of a thiosulfinate with a peroxyl radical, this reaction is endergonic because of the relative instability of the thiyl radical compared to the perthiyl radical formed in the reaction with the trisulfide-1-oxide. No corresponding TS could be located for homolytic substitution on a disulfide. 
Although we were also able to find a TS structure for substitution at the central sulfur atom of the trisulfide-1-oxide, this was significantly higher in energy (cf. Figure 8). However, while the analogous TS structure for peroxyl radical substitution on the thiosulfinate was similarly higher in energy compared to reaction on the sulfinyl sulfur, the reaction was now exergonic. Moreover, the difference of $2.5 \mathrm{kcal} / \mathrm{mol}$ in the free energy barrier between this reaction and the reaction of the trisulfide-1-oxide at the oxidized sulfur atom corresponds nicely to the 100-fold difference in rate constant measured experimentally for the two. Thus, it is likely that unactivated thiosulfinates (which do not undergo Cope elimination) react with peroxyl radicals by homolytic substitution.

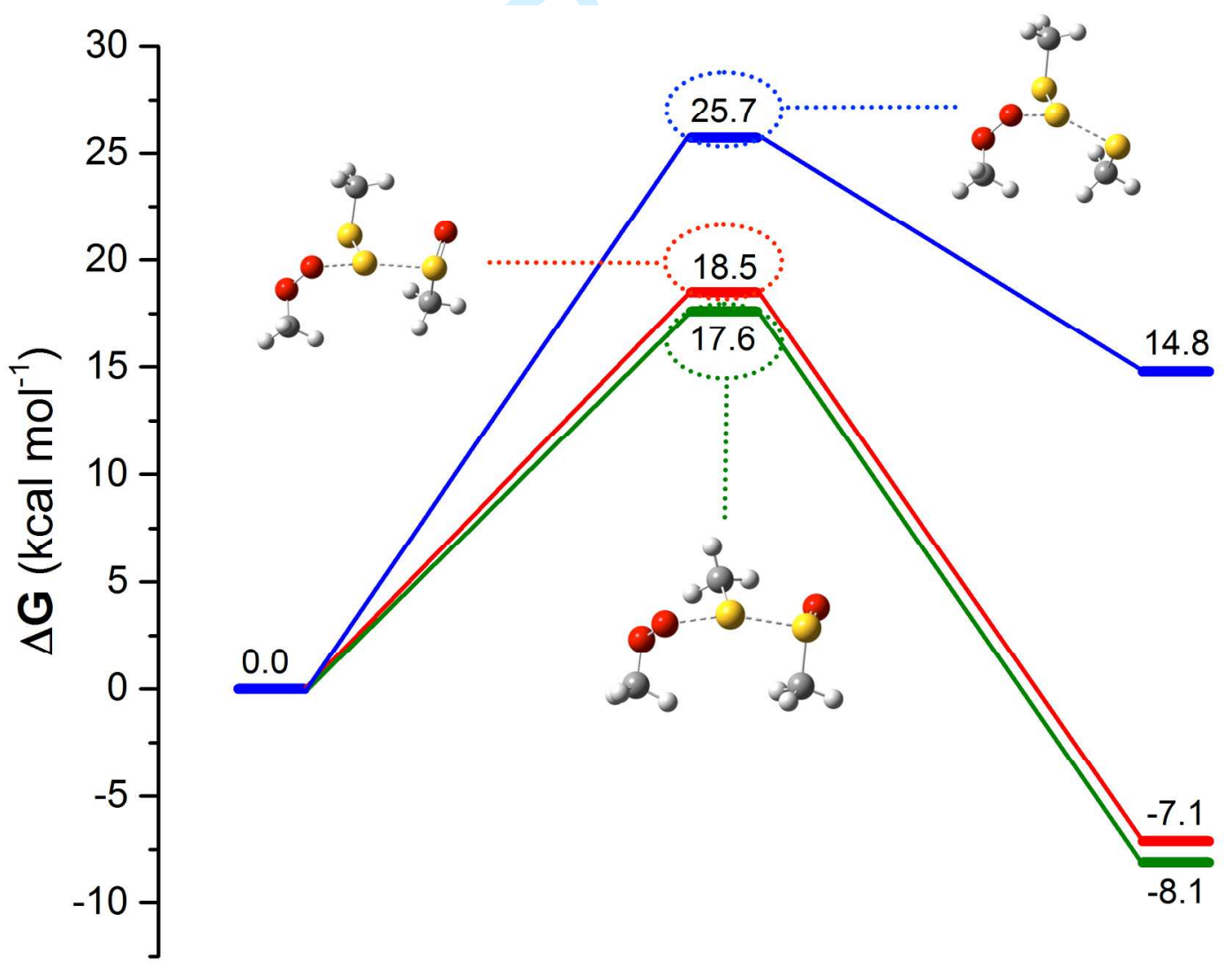


Figure 8. Methylperoxyl substitution onto $S_{2}$ of dimethyl thiosulfinate $(-)$, dimethyl trisulfide (-), and dimethyl trisulfide-1-oxide (-).

The concerted displacement of a perthiyl radical from a trisulfide-1-oxide (or thiyl radical from a thiosulfinate) by a peroxyl radical is surprising; it nominally requires the peroxyl radical to react as a nucleophile, but oxygen-centered radicals are electrophilic. Nevertheless, this mechanism accounts for why higher organosulfur compounds must be activated by ionic oxidation to their corresponding oxides to be competent RTAs.

\section{Concluding Remarks}

Our venture into organosulfur chemistry was prompted by the curious radicaltrapping activity of allicin, the odorous thiosulfinate from garlic, but has since evolved along several lines, as most good research projects do. While we uncovered that allicin's RTA activity was due to its facile Cope elimination to produce a highly reactive sulfenic acid, we subsequently found this reactivity to be irrelevant in biological contexts, where allicin appears only to induce cell death. Along the way we were able to shed light on fundamental aspects of sulfenic acid reactivity, including their intermediacy in thiol oxidation, as well as provide some significant insights into the mechanisms of peroxyl radical reactions in our studies with analogous selenenic acids. Most recently we have extended our investigations to the RTA activity of higher organosulfur compounds, which have revealed a surprising homolytic substitution mechanism for the reaction of trisulfide-1-oxides and 
(unactivated) thiosulfinates with peroxyl radicals. This accounts for the paradoxical observation that polysulfides must be oxidized to induce significant RTA activity.

\section{Acknowledgements}

We thank Keith Ingold, for making us aware of the "garlic problem" in the first place, Luca Valgimigli and Riccardo Amorati for their contributions to the EPR and inhibited autoxidation studies of petivericin and the 9-triptycenesulfenic acid, and the various Pratt group members that have contributed to these efforts since 2008.

We also thank the Natural Sciences and Engineering Research Council of Canada, the Canada Foundation for Innovation, the Canada Research Chairs program and the University of Ottawa and Queen's University for financial support.

\section{References}

(1) Denison, G. H., Jr. Ind. Eng. Chem. 1944, 36, 477.

(2) Denison, G. H., Jr; Condit, P. C. Ind. Eng. Chem. 1945, 37, 1102.

(3) Holdsworth, J. D.; Scott, G.; Williams, D. J. Chem. Soc. 1964, 4692.

(4) Bateman, L. Q. Rev., Chem. Soc. 1954, 8, 147.

(5) Ingold, K. U. Chem. Rev. 1961, 61, 563.

(6) Ingold, K. U.; Pratt, D. A. Chem. Rev. 2014, 114, 9022.

(7) Burton, G. W.; Ingold, K. U. Acc. Chem. Res. 1986, 19, 194.

(8) Block, E. Garlic and Other Alliums; Royal Society of Chemistry, 2010.

(9) Block, E. Angew. Chem. Int. Ed. 1992, 31, 1135.

(10) Cavallito, C. J.; Bailey, J. H. J. Am. Chem. Soc. 1944, 66, 1950.

(11) Prasad, K.; Laxdal, V. A.; Yu, M.; Raney, B. L. Mol. Cell. Biochem. 1995, 148, 183.

(12) Rabinkov, A.; Miron, T.; Konstantinovski, L.; Wilchek, M.; Mirelman, D.; Weiner, L. Biochim. Biophys. Acta 1998, 1379, 233.

(13) Ou, C.-C.; Tsao, S.-M.; Lin, M.-C.; Yin, M.-C. Lipids 2003, 38, 219.

(14) Okada, Y.; Tanaka, K.; Sato, E.; Okajima, H. Org. Biomol. Chem. 2006, 4, 4113.

(15) Amorati, R.; Pedulli, G. F. Org. Biomol. Chem. 2008, 6, 1103.

(16) Lynett, P. T.; Butts, K.; Vaidya, V.; Garrett, G. E.; Pratt, D. A. Org. Biomol. Chem. 2011, 9, 3320.

(17) Vaidya, V.; Ingold, K. U.; Pratt, D. A. Angew. Chem. Int. Ed. 2008, 48, 157. 
(18) Koelewijn, P.; Berger, H. Recl. Trav. Chim. Pays-Bas 1972, 91, 1275.

(19) Davis, F. A.; Jenkins, L. A.; Billmers, R. L. J. Org. Chem. 1986, 51, 1033.

(20) Freeman, F.; Kodera, Y. J. Agric. Food Chem. 1995, 43, 2332.

(21) Kubec, R.; Musah, R. A. Phytochemistry 2001, 58, 981.

(22) Kubec, R.; Kim, S.; Musah, R. A. Phytochemistry 2002, 61, 675.

(23) Amorati, R.; Lynett, P. T.; Valgimigli, L.; Pratt, D. A. Chem. Eur. J. 2012, 18, 6370.

(24) Krumova, K.; Friedland, S.; Cosa, G. J. Am. Chem. Soc. 2012, 134, 10102.

(25) Li, B.; Harjani, J. R.; Cormier, N. S.; Madarati, H.; Atkinson, J.; Cosa, G.; Pratt, D. A. J. Am. Chem. Soc. 2013, 135, 1394.

(26) Zheng, F.; Pratt, D. A. Chem. Commun. 2013, 49, 8181.

(27) Li, B.; Zheng, F.; Chauvin, J.-P. R.; Pratt, D. A. Chem. Sci. 2015, in press.

(28) Usually this is achieved via sterics (see reference 29, for example) but recent examples have made use of electronics, see: Li, X.-B.; Xu, Z.-F.; Liu, L.-J.; Liu, J.-T. Eur. J. Org. Chem. 2014, 2014, 1182.

(29) Nakamura, N. J. Am. Chem. Soc. 1983, 105, 7172.

(30) McGrath, A. J.; Garrett, G. E.; Valgimigli, L.; Pratt, D. A. J. Am. Chem. Soc. 2010, 132, 16759.

(31) Zielinski, Z.; Presseau, N.; Amorati, R.; Valgimigli, L.; Pratt, D. A. J. Am. Chem. Soc. 2014, 136, 1570.

(32) Howard, J. A.; Chenier, J. H. B. Can. J. Chem. 1975, 53, 623.

(33) Gupta, V.; Carroll, K. S. Biochim. Biophys. Acta 2014, 1840, 847.

(34) Chauvin, J.-P. R.; Pratt, D. A. In preparation.

(35) Lubricant Additives, Second Edition. Rudnick, L. R., Ed.; CRC Press, 2009.

(36) Seki, T.; Hosono, T.; Hosono-Fukao, T.; Inada, K.; Tanaka, R.; Ogihara, J.; Ariga, T. Asia Pac J Clin Nutr 2008, 17, 249.

(37) Xiao, D.; Singh, S. V. Carcinogenesis 2006, 27, 533.

(38) Kim, S.; Lee, H.-G.; Park, S.-A.; Kundu, J. K.; Keum, Y.-S.; Cha, Y.-N.; Na, H.-K.; Surh, Y.-J. PLoS ONE 2014, 9, 1.

(39) Block, E.; Dane, A. J.; Cody, R. B. Phosphorus, Sulfur Silicon Relat. Elem. 2011, 186, 1085.

(40) Chauvin, J.-P. R.; Haidasz, E. A.; Pratt, D. A. Submitted.

(41) Everett, S. A.; Wardman, P. Meth. Enzymol. 1995, 251, 55. 